\title{
APLIKASI BELAJAR ANAK PADA TK ISLAM SYAUQI BERBASIS ANDROID
}

\author{
Muhamad Syahrudin ${ }^{1}$, Gita Kencanawaty ${ }^{2}$ \\ Program Studi Teknik Informatika, Fakultas Teknik dan Ilmu Komputer, \\ Universitas Indraprasta PGRI \\ Jalan Raya Tengah No 80, Kelurahan Gedong, Pasar Rebo, Jakarta Timur \\ Msyah789@gmail.com ${ }^{1}$, Gitakencanawaty@gmail.com ${ }^{2}$
}

\begin{abstract}
Abstrak
Tujuan dari penelitian adalah untuk merancang AplikasiBelajar Anak pada TK Islam Syauqi Berbasis Androiduntuk membantu daya minat belajar anak usia dini. Dengan adanya pembelajaran baru ini dengan mengandalkan teknologi berbasis Android di harapkan anak-anak dapat belajar lebih fokus dan memahami segala macam pembelajaran alfabet, angka, bantuk, hewan, buah, warna yang terkandung di dalam aplikasi tersebut, sehingga dapat memberikan peningkatan mutu didik anak usia dini.metode yang digunakan untuk menganalisis perancangan aplikasi ini adalah metode Waterfall. Pada hasil pengujian yang dilakukan, aplikasi belajar anak yang diuji dengan kuesioner.Peneliti menarik kesimpulan bahwa sistem pembelajaran yang masih konvensional berubah menjadi suatu aplikasi untuk mempermudah siswa untuk belajar,sehingga penyampaian materi dapat dengan tepat.
\end{abstract}

Kata kunci : Android, Aplikasi Belajar, Belajar Anak, TK Islam Syauqi

\begin{abstract}
The purpose of the research is to design a Children's Learning Application at Syauqi Islamic Kindergarten based on Android to help early childhood learning interest. With this new learning by relying on Androidbased technology, it is hoped that children can learn to focus more and understand all kinds of learning the alphabet, numbers, shapes, animals, fruits, colors contained in the application, so that it can provide an increase in the quality of children's education. The method used to analyze the design of this application is the Waterfall method. In the results of the tests carried out, children's learning applications were tested by questionnaires. Researchers concluded that the conventional learning system was turned into an application to make it easier for students to learn, so that material delivery could be done correctly.
\end{abstract}

Keywords: Android, Children Learning, Learning Applications, Kindergarten. Islam Syauqi

\section{PENDAHULUAN}

Kemajuan teknologi informasi saat ini telah melahirkan budaya penggunaan gadget dalam kehidupan sehari-hari.Salah satunya gadget yang saat ini dibutuhkan banyak orang, menjadi suatu kebutuhan pokok dalam kehidupan yaitu Smartphone.Penggunaan smartphone dan teknologi pada saat ini sudah terasa sangat pesat di bidang Pendidikan.Seperti hal-nya banyak bermunculan aplikasi - aplikasi mobile pada smartphone Android.Menurut(Sutabri, 2012), aplikasi adalah suatu alat yang memiliki fungsi khusus berdasarkan kemampuan yang dimilikinya untuk membantu melakukan suatu pekerjaan bagi penggunanya.sebagai media penyampaian materi dan sebagai media praktik terhadap para peserta didik. Menurut (Chusna, 2017)Seiring berkembangnya zaman, sekarang belajar tidak hanyaterfokus dengan buku, Namun melalui gadget kita dapat mengaksesberbagai ilmu pengetahuan yang kita perlukan.Manfaat dari Pendidikan usia dini seperti taman kanak - kanak (TK) adalah dasar kearah perkembangan sikap, pengetahuan, keterampilan, dan daya cipta yang diperlukan oleh anak didik dalam menyesuaikan diri dengan lingkungannya dan untuk pertumbuhan dan pemkembangan kearah kedewasaan. menurut(Hanafy, 2014)pembelajaran adalah kegiatan yang berproses melalui tahapan perancangan, pelaksanaan, dan evaluasi. Dalam era sekarang ini anak-anak usia dini sudah mulai belajar membaca,mengeja segala bentuk pengenalan huruf, angka, warna, hewan, sampai mulai membedakan bangun datar seperti halnya membedakan bentuk persegi dan segitiga. Pada umumnya anak usia prasekolah sangat aktif 
bermain, dalam memberikan pola asuh atau metode belajar kepada anak usia prasekolah dibutuhkan suatu pembelajaran yang interaktif berupa audio visual agar anak cenderung lebih cepat tanggap, salah satu faktor pendukung pembelajaran yang interaktif adalah dengan adanya media atau fasilitas belajar yang menggunakan teknologi mobile-learning (Bursan \& Fitriyah, 2015). Hal itu semua sangat penting karena merupakan dasar kita untuk mengetahui suatu informasi. Namun pada umumnya anak-anak di TK Islam Syauqi mengalami kesulitan dalam belajar, yang disebabkan oleh pola belajar anak yang tidak terfokus pada objek belajarnya yang sifat anak usia dini yang suka bermain, bercanda, serta pihak sekolah yang masih menggunakan metode yang kurang menarik dalam hal mendidik anak, sehingga kurangnya tangkap pembelajaran yang di berikan oleh peserta didik di TK islam Syauqi, dan hampir semua anak usia dini selalu senang apabila orang tua atau orang lain memberikan gadget seperti smartphone, mereka selalu terfokus dengan smartphone itu, maka dari itu peneliti mendapat ide dengan membangun aplikasi belajar yang berbasis Android untuk membantu pembelajaran anak usia dini dengan bimbingan guru di sekolah maupun bimbingan orang tua pada saat dirumah dengan diharapkannnya anak-anak dapat belajar sambil bermain, yang pada akhirnya anak dapat mengerti apa yang harus di pelajari diusianya sekarang ini. Tujuan peneliti membangun penelitian ini yang berjudul "Aplikasi Belajar Anak pada TK islam Syauqi Berbasis Android" untuk membantu daya minat belajar anak usia dini. Menurut (Dian Anggraeni \& Kustijono, 2013), Android merupakan sistem operasi yang paling diminati di masyarakat karena memiliki kelebihan seperti sifat open source yang memberikan kebebasan para pengembang untuk menciptakan aplikasi. Dengan adanya pembelajaran baru ini dengan mengandalkan teknologi berbasis Android di harapkan anak-anak dapat belajar dan memahami segala macam pembelajaran yang terkandung di dalam aplikasi tersebut, sehingga dapat memberikan peningkatan mutu didik anak usia dini.

\section{PENELITIAN RELEVAN}

Penelitian relevan dari (Wakan, 2018). Game edukasi pengenalan pola dasar dan warna untuk anak Tk. Dalam mengembangkan aplikasinya menggunakan metode penelitian meliputi, Analisa kebutuhan, perancangan, implementasi dan pengujian. Maka dari itu,dalam hal ini peneliti berusaha untuk membuat sebuah game edukasi yang menarik dan mengajak anak-anak untuk mencoba mengenal pola dasar dan warna, yang mana game ini nantinya dibuat dengan tujuan mengubah media pembelajaran yang biasanya ditempel di dinding menjadi media elektronik berbasis aplikasi android sehingga bisa digunakan dimana saja dan kapan saja oleh para orangtua untuk anakanaknya. Mempermudah anak-anak dalam mengenal pola warna dan bentuk dengan cara yang menarik.

Penelitian relevan dari (Andini et al., 2018).Aplikasi Pembelajaran Berbasis Android untuk TK Islam.Pengembangan aplikasi ini menggunakan Metode Waterfall. Aplikasi yang sudah dibangun memiliki fitur pembelajaran tentang angka, huruf, objek anggota tubuh, hafalan doa pendek, dan surah sehari-hari. Masing-masing fitur memiliki tiga bahasa, yaitu Indonesia, Inggris, dan Arab.Studi ini telah mengembangkan aplikasi media pembelajaran untuk TK XYZ.Aplikasi ini diharapkan mampu mengatasi keterbatasan media pembelajaran dan membantu anak untuk memahami pelajaran. Aplikasi akan digunakan murid dengan pengawasan guru atau orang tua. Aplikasi yang dikembangkan dibuat berbasis Android.Platform ini dipilih karena 90\% orang tua murid di TK XYZ memakai smartphone Android. Dengan menggunakan Android, aplikasi ini akan mempermudah anak dalam memahami materi pembelajaran secara mandiri dirumah.

\section{METODE PENELITIAN}

Metode penelitian yaitu salah satu teknik atau cara mencari data, memperoleh, mengumpulkan atau mencantumkan data yang tepat digunakan untuk keperluan dan faktor-faktor yang berhubungan pada pokok pembahasan sehingga dapat suatu kebenaran atas data yang diperoleh. Peneliti menggunakan metode penelitian dari: Metode penelitian menurut (Nazruddin Safaat $\mathrm{H}$, 
2012)adalah "Penyaluran rasa ingin tahu manusia terhadap sesuatu masalah dengan perakuan tertentu (seperti memaksa, menghasut, menelaah dan mempelajari secara cermat serta sungguhsungguh)", sehingga diperoleh sesuatu (seperti mencapai kebenaran, dan sebagainya)". Sedangkan penelitian menurut (Haqi, Bay \& Heri Satria Setiawan, 2019), "Metode penelitian merupakan cara ilmiah untuk mendapatkan data dengan tujuan dan kegunaan tertentu". Metode penelitian yang digunakan oleh peneliti adalah metode grounded (grounded research). Menurut (Sugiyono, 2015), metode grounded research adalah suatu metode penelitian berdasarkan pada fakta dan menggunakan analisis perbandingan dengan tujuan mengadakan generalisasi empiris, menetapkan konsep, membuktikan teori, mengembangkan teori, pengumpulan dan analisis data di waktu yang bersamaan.Metode penelitian yang digunakan oleh peneliti adalah metode grounded (grounded research) yaitu suatu metode penelitian berdasarkan pada fakta dan empiris, menetapkan konsep, membuktikan teori, mengembangkan teori, pengumpulan dan analisis data dalam waktu yang bersamaan. Dalam riset ini merupakan sumber teori atau teori berdasarkan data. Setelah mengumpulkan data, peneliti melanjutkan proses penelitian sesuai dengan langkah-langkah pokok yang digunakan pada metode ini, yaitu menentukan masalah yang ingin diselidiki, mengumpulkan data atau informasi yang ada di lapangan, menganalisis dan menjelaskan masalah yang ditemukan serta membuat laporan hasil penelitian sesuai dengan apa yang akan di teliti. Teknik tahapan penelitian yang digunakan oleh peneliti dalam melakukan pengumpulan data : 1. Studi lapangan yaitu Merupakan Teknik pengumpulan data dengan mengadakan penelitian secara langsung pada lokasi penelitian, dalam hal ini lokasi yang dijadikan objek penelitian adalah TK Islam Syauqi. 2. Metode Interview atau wawancaraMerupakan suatu metode pengumpulan melalui langsung atau dengan melalui tatap muka dan tanya jawab secara langsung. Dalam hal ini peneliti melakukan wawancara langsung dengan objek guru dan wali murid TK Islam Syauqi. 3. Observasi Merupakan metode pengumpulan data dengan cara mengamati secara langsung kegiatan yang sedang berlangsung pada TK Islam Syauqi.4. Studi kepustakaanBertujuan untuk mempelajari daan mencari informasi untuk memahami dasar teori yang berhubungan dengan tujuan penelitian. 5. Uji CobaTahapan ini dimana perancang Aplikasi belajar anak pada TK islam Syauqi di uji coba. Mulai pemeriksaan button yang ada di menu huruf, angka, gambar dan bangun datar. Tahapan ini diperiksa satu persatu oleh perancang secara manual dan yang nantinya Aplikasi akan dicoba oleh penguji.

\section{HASIL DAN PEMBAHASAN}

Dengan melihat permasalahan yang ada di Tk. Islam Syauqi sekarang ini disebabkan oleh pola belajar anak yang tidak terfokus pada objek belajarnya yang sifat anak usia dini yang suka bermain, bercanda, serta pihak sekolah yang masih menggunakan metode yang kurang menarik dalam hal mendidik anak usia dini. Maka dari itu peneliti memperkenalkan salah satu media digital yang menarik untuk anak-anak agar menambah minat dan fokus dalam belajar memahami materi pembelajaran sehingga peneliti merancang aplikasi yang dapat digunakan untuk media pembelajaran yaitu dengan media teknologi Android.Struktur navigasi berfungsi untuk menggambarkan dengan jelas hubungan dan rantai kerja seluruhelemen yang akan digunakan dalam aplikasi. Dengan menggambarkan struktur navigasi, pembuatan aplikasi dapat tersusun dengan sistematis dan mudah. 


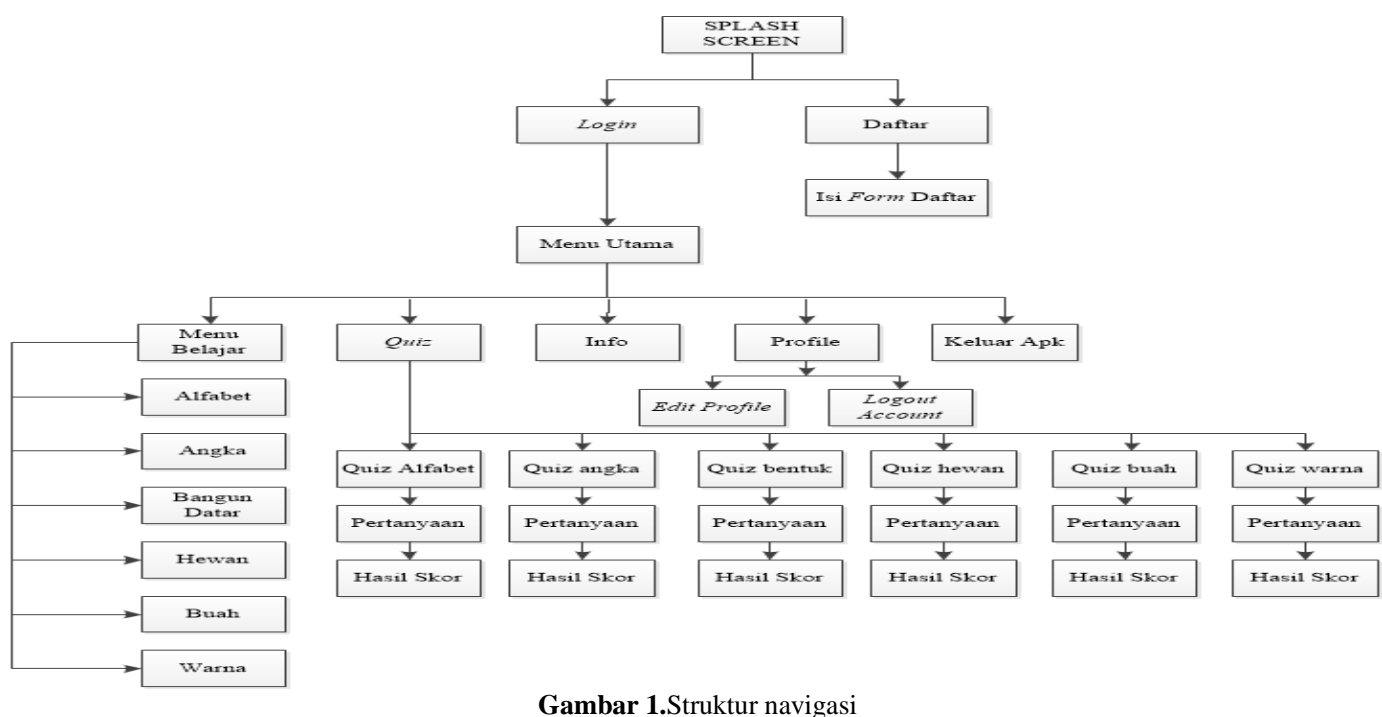

Berikut adalah perancangan flowchart untuk Aplikasi Belajar Anak Pada Tk. Islam Syauqi :

\section{Menu Splash Screen}

Flowchart

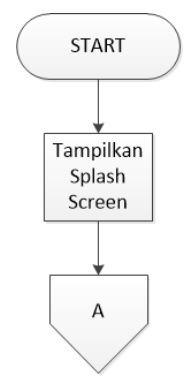

Gambar 2.Flowchart Menu Splash Screen

\section{Menu Utama}

Flowchart

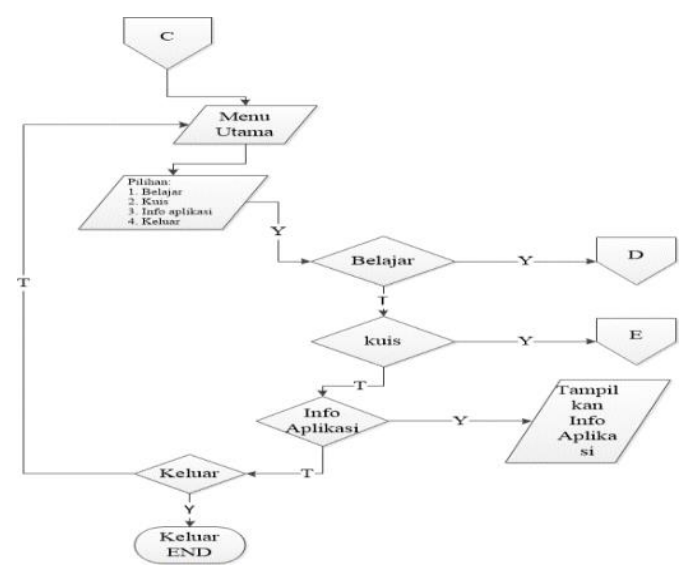

Gambar 3.Flowchart Menu Utama

Menu Belajar

Flowchart 


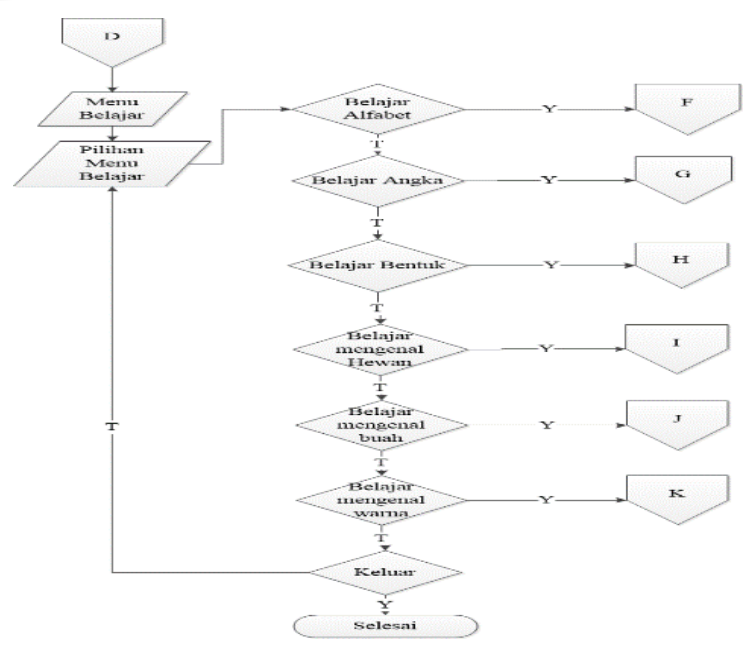

Gambar 4.Flowchart Menu Utama

\section{Menu Quiz}

Flowchart

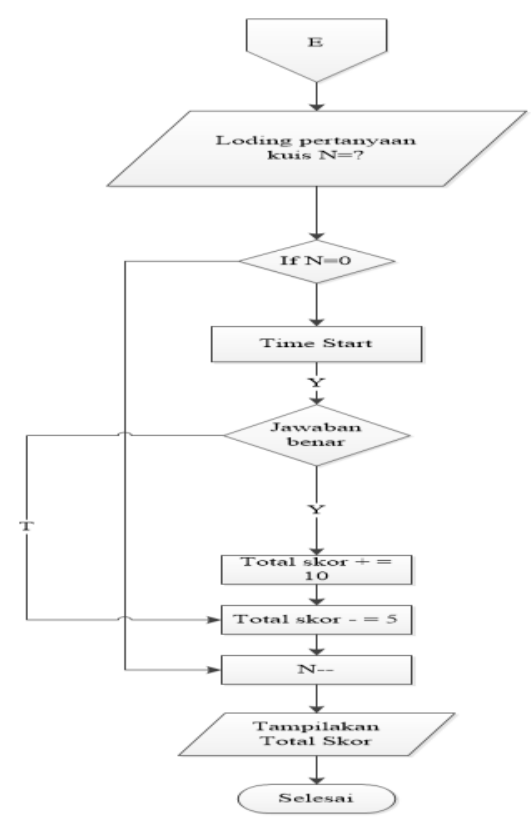

Gambar 5.Flowchart Menu Quiz

Aplikasi saat pertama kali dipilih pengguna maka akan menampilkan tampilan splashscreen. Lalu akan tampil pada halaman login, daftar apabila belum memiliki akun, setelah login berhasil maka tampilan masuk pada menu utama, yang mana jika pengguna memilih button belajar, maka akan tampil pilihan enam mata pembelajaran yaitu alfabet, angka, bangun datar, hewan, buah, dan warna. Apabila pengguna memilih buttonquiz di menu utama, maka tampilan akan berubah ke daftar pilihan quiz di setiap masing-masing pelajaran dari alfabet sampai warna. Setelah pengguna memilih salah satu quiz maka akan memunculkan pertanyaan tebak gambar yang setelah itu menjumlah nilai hasil skor di quiz tersebut, dan mengurangi poin lima di setiap pertanyaan yang salah dan menambah poin 10 di setiap jawaban yang benar dan di halaman skor quiz dengan menampilkan skor, nama, dan kelas pengguna. 


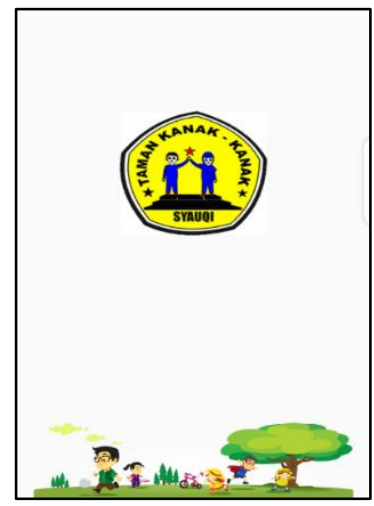

Gambar 6. Tampilan Splash Screen

Tampilan Splash Screen adalah tampilan saat aplikasi pertama dijalankan.

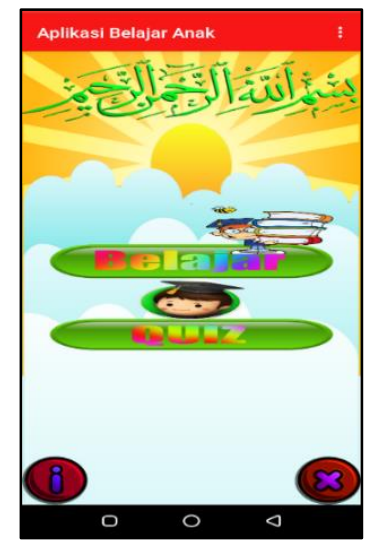

Gambar 7. Tampilan Menu Utama

Tampilan menu utamamenampikan buttonmenubelajar, button menu quiz, button info aplikasi dan, button exit.

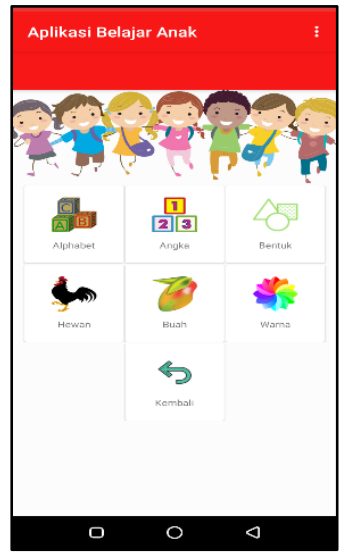

Gambar 8. Tampilan Menu Belajar

Pada tampilan menu belajar menampilkan pilihan menu belajar yaitu, alfabet, angka, bentuk, hewan, buah, warna dan button back. 


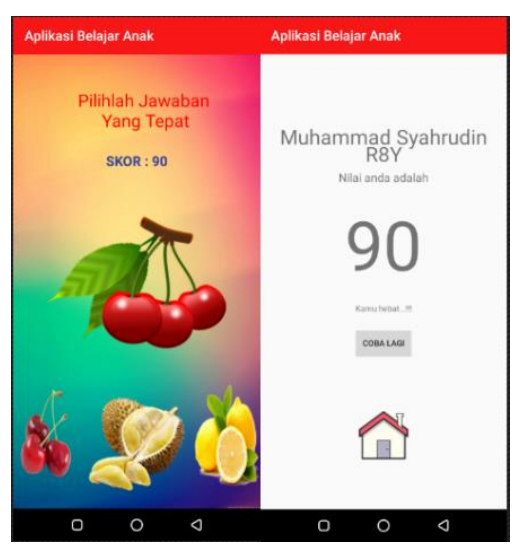

Gambar 9. Tampilan Menu Quizdengan skor

Pada tampilan menu quiz menampilkan pertanyaan dan di random pertanyaan di setiap kali uji quiz,pertanyaan berbentuk gambar dengan 3 pilihan, jawabanmenampilkan skor di setiap jawaban yang benar maka skor bertambah 10 point dan apabila jawaban salah maka skor berkurang lima point.

\section{SIMPULAN}

Berdasarkan uraian diatas dan anlisa, maka pada laporan penelitian ini yang berjudul "Aplikasi Belajar Anak pada Tk. Islam Syauqi Berbasis Android" dapat diambil kesimpulan sebagai berikut: Dengan dibuatnya aplikasi belajar anak Pada Tk. Islam Syauqi ini, siswa Tk.islam Syauqi menjadi lebih fokus dalam mengusai pembelajaran alfabet, angka, bantuk, hewan, buah, dan warna yang terkandung di dalam aplikasi dibantu dengan suara disetiap pelajaran tersebut, serta membatu para guru dan orang tua walimurid dalam mendidik anak- anak usia dini, sehingga memudahkan anakanak dalam belajar dan meningkatkan mutu didik anak usia dini di Tk. Islam Syauqi.

\section{DAFTAR PUSTAKA}

Andini, F. R., Permana, I., \& Salisah, F. N. (2018). An Nation : Aplikasi Pembelajaran Berbasis Android untuk TK Islam. Seminar Nasional Teknologi Informasi, Komunikasi Dan Industri (SNTIKI-10), November, 101-106.

Bursan, \& Fitriyah. (2015). Perancangan Permainan ( Game ) Edukasi Belajar Membaca Pada Anak Prasekolah Berbasis Smartphone. Jurnal TEKNOIF, 3(1), 62-70.

Chusna, P. A. (2017). Pengaruh Media Gadget Pada Perkembangan Karakter Anak. Dinamika Penelitian: Media Komunikasi Sosial Keagamaan, 17(2), 315-330. https://doi.org/10.21274/dinamika/2017.17.2.315-330

Dian Anggraeni, R., \& Kustijono, R. (2013). Pengembangan Media Animasi Fisika Pada Materi Cahaya Dengan Aplikasi Flash Berbasis Android. Jurnal Penelitian Fisika Dan Aplikasinya (JPFA). https://doi.org/10.26740/jpfa.v3n1.p1118

Hanafy, M. S. (2014). Konsep Belajar Dan Pembelajaran. Lentera Pendidikan : Jurnal Ilmu Tarbiyah Dan Keguruan, 17(1), 66-79. https://doi.org/10.24252/lp.2014v17n1a5

Nazruddin Safaat H. (2012). Android: Pemrograman Aplikasi Mobile Smartphone dan Tablet PC Berbasis Android (Edisi Revisi). In Android.

Pebriana, P. H. (2017). Analisis Penggunaan Gadget terhadap Kemampuan Interaksi Sosial pada Anak Usia Dini. Jurnal Obsesi : Jurnal Pendidikan Anak Usia Dini, 1(1), 1.

Sugiyono. (2015). Metode Penelitian. Metode Penelitian.

Sutabri, T. (2012). Analisis Sistem Informasi. In Analisa Sistem Informasi.

Wakan, M. Q. (2018). Game Edukasi Pengenalan Pola Dasar Dan Warna Untuk Anak TK. Universitas Islam Indonesia. 